\title{
ENETS Consensus Recommendations for the Standards of Care in Neuroendocrine Neoplasms: Follow-Up and Documentation
}

\author{
U. Knigge $^{\text {a }}$ J. Capdevila ${ }^{\text {b }}$ D.K. Bartsch ${ }^{\text {C }}$ E. Baudin ${ }^{d}$ J. Falkerby ${ }^{\mathrm{e}}$ \\ $\begin{array}{lll}\text { R. Kianmanesh } & \text { B. Kos-Kudlag } & \text { B. Niederle } \\ \text { h } & \text { E. Nieveen van Dijkum }\end{array}$ \\ D. O'Toole ${ }^{j} \quad$ A. Pascher ${ }^{k} \quad$ N. Reed' ${ }^{\prime}$ A. Sundin ${ }^{m} \quad$ M.-P. Vullierme ${ }^{n}$ all other
} Antibes Consensus Conference participants

\begin{abstract}
a Departments of Surgery and Clinical Endocrinology, Rigshospitalet, Copenhagen University Hospital, Copenhagen,

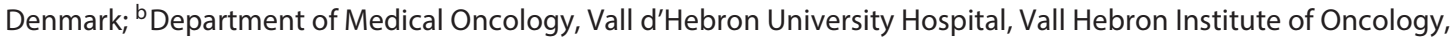
Universitat Autònoma de Barcelona, Barcelona, Spain; ${ }^{\circ}$ Department of Visceral, Thoracic and Vascular Surgery, Philipps University, Marburg, Germany; d Service de Médecine Nucléaire et de Cancérologie Endocrinienne, Institut Gustave Roussy, Villejuif, France; e Department of Endocrine Oncology, Uppsala University Hospital, Uppsala, Sweden; ${ }^{f}$ Department of General, Digestive and Endocrine Surgery, R. Debré University Hospital, Reims, France; g Department of Endocrinology, Medical University of Silesia, Katowice, Poland; 'h Section of Endocrine Surgery, Division of General Surgery, Department of Surgery, Medical University of Vienna, Vienna, Austria; 'Department of Surgery, Academic Medical Center, Amsterdam, The Netherlands; ${ }^{j}$ National Centre for Neuroendocrine Tumours, St. Vincent's University Hospital and Department of Clinical Medicine, St. James Hospital and Trinity College, Dublin, Ireland; ${ }^{k}$ Department of General, Visceral and Transplant Surgery, Charité Universitätsmedizin Berlin, Berlin, Germany; 'Beatson Oncology Centre, Gartnavel General Hospital, Glasgow, UK; m Department of Radiology

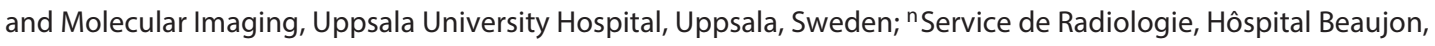
Clichy, France
\end{abstract}

\section{Keywords}

Neuroendocrine neoplasm - Neuroendocrine tumor .

Neuroendocrine carcinoma · Follow-up - TNM staging $\cdot$ Chromogranin A · Neuron-specific enolase . 5-Hydroxyindoleacetic acid · NT-pro-brain natriuretic peptide $\cdot$ Functional imaging $\cdot$ Somatostatin receptor imaging

\section{Abstract}

ENETS consensus recommendations for the standards of care in neuroendocrine neoplasms (NEN) concerning follow-up and documentation are considered in this review. The docu- mentation of patients with NEN should include the most relevant data characterizing an individual patient from the first contact with his/her physician/hospital until his/her last presentation during follow-up. It is advocated that follow-up occurs in specialized NEN centers with regular NEN tumor boards with expert panels. The follow-up should be in accordance with the ENETS consensus guidelines from 2011 and 2016, the present and coming WHO classification and ENETS/ UICC recommendations for TNM staging. The recommendations for follow-up in patients with thymic, bronchopulmonary and gastroenteropancreatic NEN are given in Table 1. However, it should be stressed that evidence-based studies for follow-up are largely missing.

(c) 2017 S. Karger AG, Basel

\section{KARGER}

(C) 2017 S. Karger AG, Basel 


\section{Introduction}

The documentation of patients with neuroendocrine neoplasms (NEN) should include the most relevant data characterizing an individual patient from the first contact with his/her physician/hospital until his/her last presentation during follow-up. The documentation should be both simple but nevertheless as complete as possible and should include basic demographic details to identify a specific patient, family history, tumor histology and biology, course of the disease, tumor board evaluations, diagnostic tests, and therapeutic interventions. Additional data about biological samples, such as tumor specimens preserved in paraffin-embedded or fresh frozen samples and the patient's samples like blood or serum, would be of high interest for current and future translational research. This information is essential for treatment and follow-up strategies adjusted to the specific features of the tumor of the patient. Furthermore, standardized documentation acts as a key precondition to learn more about patients with specific tumor subtypes and regarding the impact of treatment modalities on the course of the disease. In the present clinical setting, the timing of data collection and content of documented data vary considerably. Therefore, comparison of data from different centers is frequently hampered by lack of data uniformity.

During the ENETS Standards of Care Conference Advisory Board meeting organized in Antibes, France in 2015 , a group of physicians with extensive experience in the clinical care of patients with gastroenteropancreatic (GEP), bronchopulmonary (BP) and thymic NEN met to write recommendations on the unified collection of data and suggested time intervals for follow-up investigations. These guidelines recognize the diversity of tumor subtypes, the actual WHO and TNM classifications, the individual clinical course of the disease as well as the resource implications relevant to the growing costs of the European health care systems. Particular attention was paid to recommend only those investigations that would have a significant impact on further therapeutic strategies.

It is advocated that follow-up occurs in specialized NEN centers or at least in hospitals with close collaboration with specialized NEN centers. It is of minor importance which specialty (e.g., oncology, gastroenterology, endocrinology, pulmonology or surgery) follows the patient as long as experienced NEN specialists are present. Regularly NEN tumor boards with expert panels are essential for follow-up. Besides all new patients, patients

ENETS: Follow-up and Documentation with recurrence or progression as well as patients with other relevant problems during follow-up should be presented at the multidisciplinary tumor board.

\section{Documentation at Follow-Up Should Adhere to the Present WHO Classification and Recognize the ENETS Consensus Guidelines and Recommendations for TNM Staging}

The panel agreed that the following categories best define the different tumor entities observed in the clinical setting. The categories follow the WHO 2010 classification [1] as well as the ENETS consensus guidelines from 2011 [2] and 2016 [3] and the recommendations for TNM staging $[4,5]$ in order to better compare data from different centers. We are aware that a revised WHO classification will be published within the next few years, also considering G3 neuroendocrine carcinomas (NEC G3, poorly differentiated) versus $\mathrm{G} 3$ neuroendocrine tumors (NET G3, well differentiated) as different entities based upon differentiation. This may refine the current classifications, if an objective definition of differentiation is achieved. This subclassification may have an impact on treatment, but may not change the general follow-up procedures and recommendations. It should be stressed that evidence-based studies for follow-up are largely missing.

In this article, we have revised the previous recommendations [6] and introduced a new set-up, which we find easier to apply on the daily routine for follow-up on patients with GEP, BP and thymic NEN (Table 1). For BP NEN, typical and atypical carcinoids as well as large-cell neuroendocrine carcinomas have been included as per ENETS guidelines [7] and Danish guidelines [8]. Smallcell lung cancer is not included in the article as it is beyond the scope of these recommendations and as it is dealt with in several other guidelines. We have included a suggested follow-up regime for thymic NEN, although evidence for follow-up in these tumor types is lacking.

Firstly, the different NEN are divided according to the organ of the primary tumor, including cancer of unknown primary. Secondly, the tumors are recorded according to their grading (GEP NEN), differentiation (thymic and BP NEN), status, and operative outcome, respectively (Table 1). Data on stage (TNM - including size of the primary but also tumor burden), tumor aggressiveness (stable vs. progressive disease), functionality, chromogranin A ( $\mathrm{CgA})$ levels, and hereditary disease, which all may have an impact and thus may affect the follow-up

Neuroendocrinology 2017;105:310-319 311 
Table 1. Tumor-specific recommendations for follow-up (in most cases life-long)

\begin{tabular}{|c|c|c|c|c|c|c|c|c|c|c|}
\hline Organ & Status & F-U & Every & $\mathrm{CgA}$ & Markers $^{\mathrm{a}}$ & Endoscopy & CT/MRI/US ${ }^{\mathrm{b}}$ & $\mathrm{SRI}^{\mathrm{c}}$ & FDG-PET & Comments \\
\hline \multicolumn{11}{|c|}{ Bronchopulmonary } \\
\hline Typical & resected & yes & $6-12 m$ & yes & $\begin{array}{l}5 \text {-HIAA }{ }^{\mathrm{d}} \\
\text { relevant tumor } \\
\text { hormones }^{\mathrm{d}}\end{array}$ & $\begin{array}{l}\text { bronchoscopy } \\
5-10 y\end{array}$ & $6-12 m$ & $\begin{array}{l}12- \\
36 \mathrm{~m}^{\mathrm{e}}\end{array}$ & & $\begin{array}{l}\text { EBUS may be required if } \\
\text { recurrence is suspected }\end{array}$ \\
\hline Typical & $\begin{array}{l}\text { residual tumor } \\
\text { or metastases }\end{array}$ & yes & $3-6 m$ & yes & $\begin{array}{l}5 \text {-HIAA } \\
\text { relevant tumor } \\
\text { hormones }^{\mathrm{d}}\end{array}$ & $\begin{array}{l}\text { bronchoscopy } \\
5-10 y\end{array}$ & $3-6 m$ & $\begin{array}{l}12- \\
36 \mathrm{~m}^{\mathrm{e}}\end{array}$ & $\begin{array}{l}12- \\
24 \mathrm{~m}^{1}\end{array}$ & $\begin{array}{l}\text { EBUS may be required if } \\
\text { progression is suspected }\end{array}$ \\
\hline Atypical & resected & yes & $3-6 m$ & yes & $\begin{array}{l}\text { 5-HIAA }{ }^{\mathrm{d}} \\
\text { relevant tumor } \\
\text { hormones }^{\mathrm{d}}\end{array}$ & $\begin{array}{l}\text { bronchoscopy }{ }^{\mathrm{m}} \\
1-3 \mathrm{y}\end{array}$ & (3) $-6 \mathrm{~m}$ & $\begin{array}{l}12- \\
24 \mathrm{~m}^{\mathrm{e}, \mathrm{f}}\end{array}$ & $\begin{array}{l}12- \\
24 \mathrm{~m}^{1}\end{array}$ & $\begin{array}{l}\text { EBUS may be required if } \\
\text { recurrence is suspected }\end{array}$ \\
\hline Atypical & $\begin{array}{l}\text { residual tumor } \\
\text { or metastases }\end{array}$ & yes & $3 \mathrm{~m}$ & yes & $\begin{array}{l}5 \text {-HIAA }^{\mathrm{d}} \\
\text { relevant tumor } \\
\text { hormones }^{\mathrm{d}}\end{array}$ & $\begin{array}{l}\text { bronchoscopy }^{\mathrm{m}} \\
1-3 \mathrm{y}\end{array}$ & $3-6 m$ & $\begin{array}{l}12- \\
24 \mathrm{~m}^{\mathrm{e}, \mathrm{f}}\end{array}$ & $\begin{array}{l}12- \\
24 \mathrm{~m}^{1}\end{array}$ & $\begin{array}{l}\text { EBUS may be required if } \\
\text { progression is suspected }\end{array}$ \\
\hline $\begin{array}{l}\text { LCNEC } \\
\text { poorly diff. }\end{array}$ & $\begin{array}{l}\text { resected/ } \\
\text { nonresected }\end{array}$ & yes & $2-3 m$ & yes $^{\mathrm{d}}$ & $\begin{array}{l}\text { NSE }^{\mathrm{d}} \\
\text { relevant tumor } \\
\text { hormones }\end{array}$ & $\begin{array}{l}\text { bronchoscopy } \\
\text { if symptoms }\end{array}$ & $2-3 m$ & $\begin{array}{l}12- \\
24 \mathrm{~m}^{\mathrm{e}, \mathrm{f}}\end{array}$ & $\begin{array}{l}12- \\
24 \mathrm{~m}^{1}\end{array}$ & $\begin{array}{l}\text { bronchoscopy indicated if } \\
\text { rebiopsy, argon-beam or } \\
\text { bronchial stent is required; } \\
\text { EBUS may be required if } \\
\text { recurrence or progression is } \\
\text { suspected }\end{array}$ \\
\hline
\end{tabular}

Thymic

Typical

resected/ yes $6-12 \mathrm{~m}$ yes relevant tumor

hormones $^{\mathrm{d}}$

$6-12 \mathrm{~m}$

$12-\quad 12-$

\begin{tabular}{ll}
$\begin{array}{l}\text { residual tumor } \\
\text { or metastases }\end{array}$ \\
\hline Atypical
\end{tabular}

\begin{tabular}{ll}
\hline Atypical & resected/ \\
residual tumor
\end{tabular}

or metastases

Poorly diff.

resected/

yes $3-6 \mathrm{~m}$ yes relevant tumor

hormones $^{\mathrm{d}}$

$36 \mathrm{~m}^{\mathrm{e}, \mathrm{f}} \quad 36 \mathrm{~m}^{\mathrm{e}, \mathrm{f}}$

Esophagus

nonresected

relevant tumor

hormones $^{\mathrm{d}}$

6-

$24 \mathrm{~m}^{\mathrm{e}, \mathrm{f}} \quad 24 \mathrm{~m}^{\mathrm{e}, \mathrm{f}}$

\begin{tabular}{|c|c|c|c|c|c|c|c|c|c|}
\hline G1-G2 NET & $\begin{array}{l}\text { resected/ } \\
\text { nonresected }\end{array}$ & yes & $3 \mathrm{~m}$ & yes $^{\mathrm{d}}$ & none & $\begin{array}{l}12 \mathrm{~m} \\
\text { or symptoms }\end{array}$ & $3-6 m$ & $\begin{array}{l}12- \\
24 \mathrm{~m}^{\mathrm{e}}\end{array}$ & \\
\hline G3 NEC & $\begin{array}{l}\text { resected/ } \\
\text { nonresected }\end{array}$ & yes & $3 \mathrm{~m}$ & yes $^{\mathrm{d}}$ & none & $\begin{array}{l}12 \mathrm{~m} \text {, } \\
\text { or symptoms }\end{array}$ & $2-3 m$ & $\begin{array}{l}12- \\
24 \mathrm{~m}^{\mathrm{e}, 6}\end{array}$ & $\begin{array}{l}6- \\
24 \mathrm{~m}^{1}\end{array}$ \\
\hline
\end{tabular}

EUS may be required if

recurrence or progression is suspected

EUS may be required if

recurrence or progression is suspected

\begin{tabular}{|c|c|c|c|c|c|c|c|c|c|c|}
\hline $\begin{array}{l}\text { Stomach } \\
\text { Type } 1 \\
\text { G1-G2 NET }\end{array}$ & $\begin{array}{l}\text { resected/ } \\
\text { nonresected }\end{array}$ & yes & $6-12 \mathrm{~m}$ & yes $^{g}$ & $\begin{array}{l}\text { gastring }^{g} \\
\mathrm{~B}_{12} \text { vitamin }\end{array}$ & $\begin{array}{l}12 \mathrm{~m} \text {, } \\
\text { or symptoms }\end{array}$ & no ${ }^{h}$ & no ${ }^{h}$ & no & $\begin{array}{l}\text { EUS may be required if } \\
\text { recurrence or progression is } \\
\text { suspected }\end{array}$ \\
\hline $\begin{array}{l}\text { Type } 2 \\
\text { G1-G2 }\end{array}$ & $\begin{array}{l}\text { resected/ } \\
\text { nonresected }\end{array}$ & yes & $6-12 m$ & yes & $\begin{array}{l}\text { gastrin } \\
\mathrm{Ca}^{2+}, \mathrm{PTH}\end{array}$ & $\begin{array}{l}6-12 \mathrm{~m}, \\
\text { or symptoms }\end{array}$ & $12 \mathrm{~m}$ & $\begin{array}{l}12- \\
24^{\mathrm{me}, \mathrm{f}}\end{array}$ & no & $\begin{array}{l}\text { EUS may be required if } \\
\text { recurrence or progression is } \\
\text { suspected }\end{array}$ \\
\hline $\begin{array}{l}\text { Type } 3 \\
\text { G1-G3 NEC/NET }\end{array}$ & $\begin{array}{l}\text { resected/ } \\
\text { nonresected }\end{array}$ & yes & $2-3 m$ & yes $^{\mathrm{d}}$ & none & $\begin{array}{l}6-12 \mathrm{~m}, \\
\text { or symptoms }\end{array}$ & $2-6 m$ & $\begin{array}{l}12- \\
24 \mathrm{~m}^{\mathrm{e}, \mathrm{f}}\end{array}$ & $\begin{array}{l}12- \\
24 \mathrm{~m}^{1}\end{array}$ & $\begin{array}{l}\text { EUS may be required if } \\
\text { recurrence or progression is } \\
\text { suspected }\end{array}$ \\
\hline
\end{tabular}

\begin{tabular}{llllllll}
\hline $\begin{array}{l}\text { Duodenum } \\
\text { Gastrinoma }\end{array}$ & resected & yes & $6-12 \mathrm{~m} \quad$ yes & gastrin, & $12 \mathrm{~m}$, & $12 \mathrm{~m}$ & 12
\end{tabular}

$\begin{array}{llllllll}\text { Gastrinoma } & \text { resected } & \text { yes } & 6-12 \mathrm{~m} & \text { yes } & \begin{array}{l}\text { gastrin, } \\ \mathrm{Ca}^{2+}, \mathrm{PTH}\end{array} & \begin{array}{l}12 \mathrm{~m}, \\ \text { or symptoms }\end{array} & 12 \mathrm{~m}\end{array}$

$4 \mathrm{~m}^{\mathrm{e}}$

Gastric $\mathrm{pH}$ measurement or secretin test may be performed if symptoms recur; EUS may be required if recurrence is suspected

\begin{tabular}{|c|c|c|c|c|c|c|c|c|c|c|}
\hline $\begin{array}{l}\text { Gastrinoma } \\
\text { G1-G2 }\end{array}$ & nonresected & yes & $3-6 m$ & yes & $\begin{array}{l}\text { gastrin, } \\
\mathrm{Ca}^{2+}, \mathrm{PTH}\end{array}$ & $\begin{array}{l}6-12 \mathrm{~m}, \\
\text { or symptoms }\end{array}$ & $6-12 \mathrm{~m}$ & $\begin{array}{l}12- \\
24 \mathrm{~m}^{\mathrm{e}}\end{array}$ & & $\begin{array}{l}\text { EUS may be required if } \\
\text { progression is suspected }\end{array}$ \\
\hline $\begin{array}{l}\text { Other } \\
\text { G1-G2 NET }^{\text {n }}\end{array}$ & $\begin{array}{l}\text { resected/ } \\
\text { nonresected }\end{array}$ & yes & $3-6 m$ & yes $^{d}$ & $\begin{array}{l}\text { relevant tumor } \\
\text { hormones }^{\mathrm{d}}\end{array}$ & $\begin{array}{l}12 \mathrm{~m} \text {, } \\
\text { or symptoms }\end{array}$ & $6-12 m$ & $\begin{array}{l}12- \\
24 \mathrm{~m}^{\mathrm{e}}\end{array}$ & & $\begin{array}{l}\text { EUS may be required if } \\
\text { recurrence or progression is } \\
\text { suspected }\end{array}$ \\
\hline G3 NEC/NET ${ }^{n}$ & $\begin{array}{l}\text { resected/ } \\
\text { nonresected }\end{array}$ & yes & $3 \mathrm{~m}$ & yes $^{\mathrm{d}}$ & none & $\begin{array}{l}12 \mathrm{~m} \text {, } \\
\text { or symptoms }\end{array}$ & $3 \mathrm{~m}$ & $\begin{array}{l}12- \\
24 \mathrm{~m}^{\mathrm{e}, \mathrm{f}}\end{array}$ & $\begin{array}{l}12- \\
24 \mathrm{~m}^{1}\end{array}$ & $\begin{array}{l}\text { EUS may be required if } \\
\text { recurrence or progression is } \\
\text { suspected }\end{array}$ \\
\hline
\end{tabular}


Table 1 (continued)

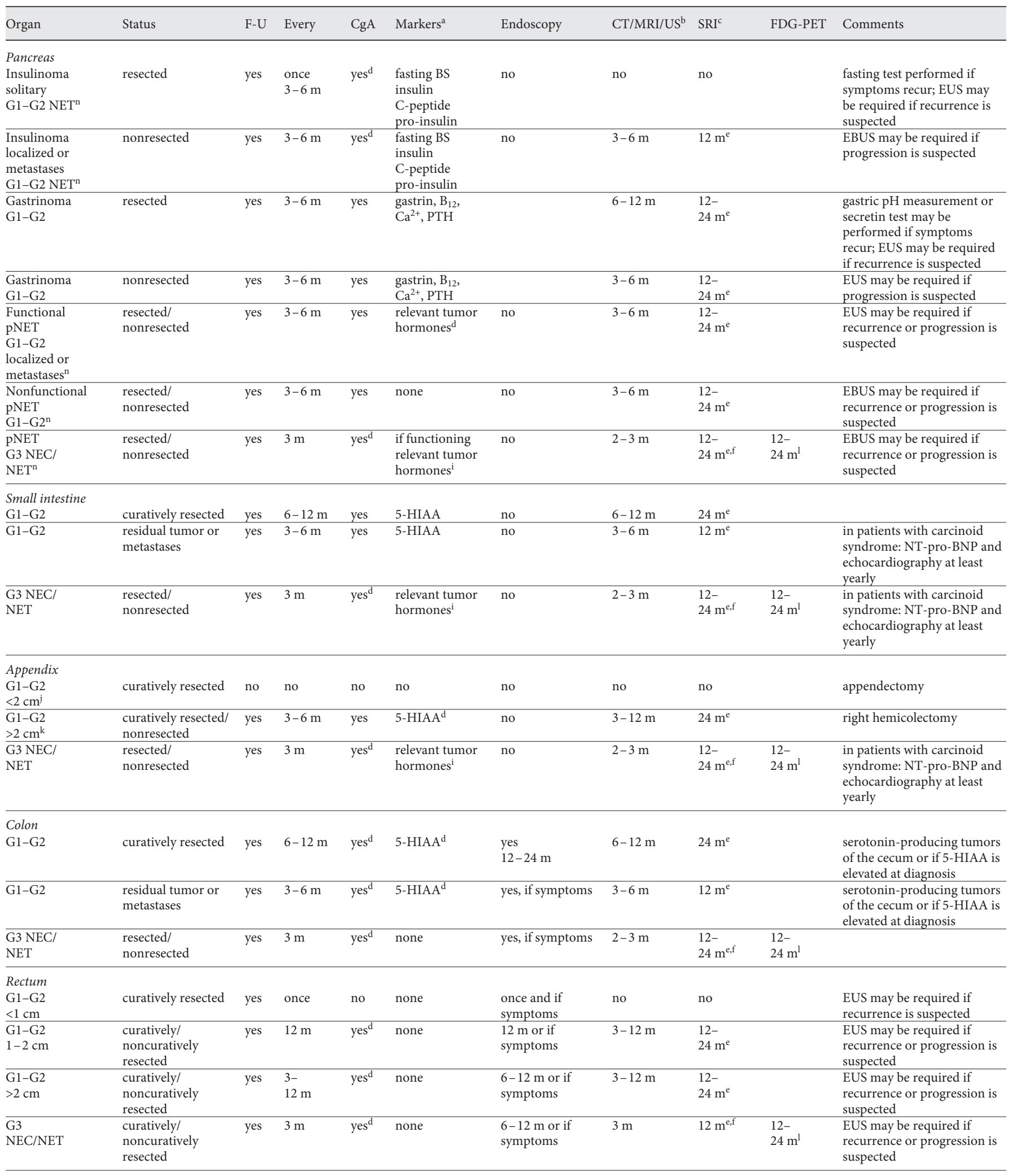


Table 1 (continued)

\begin{tabular}{|c|c|c|c|c|c|c|c|c|c|c|}
\hline Organ & Status & $\mathrm{F}-\mathrm{U}$ & Every & $\mathrm{CgA}$ & Markers $^{\mathrm{a}}$ & Endoscopy & $\mathrm{CT} / \mathrm{MRI} / \mathrm{US}^{\mathrm{b}}$ & $\mathrm{SRI}^{\mathrm{c}}$ & FDG-PET & Comments \\
\hline \multicolumn{11}{|c|}{ Cancer - unknown primary } \\
\hline G1-G2 & $\begin{array}{l}\text { noncuratively } \\
\text { resected }\end{array}$ & yes & $3-6 m$ & yes $^{\mathrm{d}}$ & 5-HIAA ${ }^{\mathrm{d}}$ & no & $3-6 m$ & $12 \mathrm{~m}^{\mathrm{e}}$ & & \\
\hline $\begin{array}{l}\text { G3 NEC/ } \\
\text { NET }\end{array}$ & $\begin{array}{l}\text { noncuratively } \\
\text { resected }\end{array}$ & yes & $3 \mathrm{~m}$ & yes $^{d}$ & 5 -HIAA ${ }^{\mathrm{d}}$ & no & $3 \mathrm{~m}$ & $12 \mathrm{~m}^{\mathrm{e}, \mathrm{f}}$ & $\begin{array}{l}12- \\
24 \mathrm{~m}^{1}\end{array}$ & \\
\hline
\end{tabular}

LNEC, large-cell neuroendocrine carcinomas; NET, neuroendocrine tumor; NEC, neuroendocrine carcinoma; pNET, pancreatic neuroendocrine tumor; F-U, follow-up; m, months; NSE, neuron-specific enolase; PTH, parathyroid hormone; BS, blood sugar; y, years; EBUS, endobronchial ultrasound; EUS, endoscopic ultrasound.

${ }^{a}$ Other tumor markers and hormones in blood and urine. ${ }^{b} \mathrm{CT}$ is preferred for routine control. ${ }^{\mathrm{c}}$ Somatostatin receptor imaging $\left({ }^{68} \mathrm{Ga}-\mathrm{DOTA}\right.$ PET; octreotide scintigraphy). ${ }^{\mathrm{d}}$ Only if elevated at diagnosis. ${ }^{\mathrm{e}}$ Only if positive at diagnosis. ${ }^{\mathrm{f}}$ In G3 NEC or atypical pulmonary NET, ${ }^{18}$ FDG-PET may be used instead. ${ }^{\mathrm{g}}$ Are usually elevated, but have no implement on F-U. ${ }^{\mathrm{h}}$ Only if metastasized; for CT/MRI/US every 6 months, for SRI every $12-24$ months. ${ }^{\mathrm{i}}$ Rarely functioning. ${ }^{j}$ No metastases, no angioinvasion, mesoappendiceal invasion $<3$ mm. ${ }^{\mathrm{k}}$ Or metastases, angioinvasion, mesoappendiceal invasion $>3 \mathrm{~mm}$, localized at the base, uncertain resection margins. ${ }^{1}$ FDG-PET-CT may be used instead of SRI if positive at diagnosis. ${ }^{\mathrm{m}}$ Only if tumor is visible by bronchoscopy at diagnosis. ${ }^{\mathrm{n}}$ Hereditary diseases (MEN-1, VHL and neurofibromatosis type 1 is included).

intervals, are too comprehensive to be included in Table 1 , but are mentioned in Table 2 .

Functioning tumors (the specific secreted hormone being their tumor marker) should be followed up with hormone analyses and imaging every $3-12$ months depending on hormone-related symptoms and tumor aggressiveness. If recurrence or persistence is highly suspected, functional tests, for example fasting test for insulinomas and secretin test for gastrinomas, may be required.

\section{Recommendations for Follow-Up Investigations}

It is recommended that follow-up should be performed in specialized NEN centers to obtain specific biochemistry and high-quality imaging.

\section{General Recommendations}

Documentation of each patient should encompass:

- Patient identification and basic demographic details

- General health score (Karnofsky status/WHO score/ ECOG performance status)

- Patient's history: onset, extent, and severity of tumorspecific symptoms, hormone-related syndromes, family history, inherited syndromes, metachronous or synchronous malignancies

- Comorbidity including concomitant diseases, including kidney and liver disease

- Plasma CgA and relevant hormone levels with reference to previous levels considering the current unspecific medical treatment of the patient (e.g., proton pump inhibitors may induce elevation of plasma $\mathrm{CgA}$ and gastrin levels)

- Presence of carcinoid heart disease

- Availability of tumor and/or patient samples, including characteristics of the samples and location
Table 2. Shorter intervals between follow-ups in patients with NEN

High-grade tumors

Large tumor burden (e.g., liver burden $>30 \%$ and lung/ bone metastases)

Extensive disease

Aggressive behavior (progression within few months)

Severe (uncontrolled) endocrine symptoms

Weight loss and clinical aggravation

High chromogranin A levels $>10$ UNL

UNL, upper normal level.

- Pathological diagnosis including TNM stage (ENETS and UICC) and WHO grade (mitotic count or preferred Ki-67 proliferation index) from resected tumor specimens or from biopsies from targeted organs

- Development of tumor and metastases and changes in tumor burden based on computerized tomography/ magnetic resonance imaging (CT/MRI) and somatostatin receptor imaging (SRI); for SRI, up-take grade should be recorded

- Preceding and actual treatment(s)

- Consider referral to curative or debulking surgery

- Consider referral to medical treatment

- Consider referral to peptide receptor radionuclide treatment

- Consider referral to liver-directed interventional treatment

- Consider referral to palliative unit for supportive care If relevant from the above, the patient documentation should be presented at the multidisciplinary tumor board for further planning.
Knigge et al. 


\section{General Comments}

Tumor-specific follow-up investigations are mainly based on clinical symptoms, imaging procedures such as functional and cross-sectional imaging, and tumor markers. However, an expert physician who is in charge of an individual patient is able to judge the patient's general health and even prognosis by a careful history and examination, assessment of weight loss, muscular mass and symptoms, for example heart function in cases of the carcinoid syndrome and possible carcinoid cardiac disease. However, these items are difficult to compare inter- and intraindividually and should be supported where possible by "objective" procedures such as imaging methods and serum/plasma tumor markers.

\section{Tumor Markers}

\section{Chromogranin A}

At present, the most common and reliable tumor marker is plasma CgA for patients with G1 and G2 NEN. However, plasma $\mathrm{CgA}$ is generally normal in patients with nonfunctioning duodenal NEN, appendiceal NEN, small rectal NEN and insulinomas and is often normal in patients with localized G1 and G2 NEN and in patients with G3 NEN (some G3 NET can have increased CgA plasma levels). Plasma CgA may reflect tumor mass and changes in tumor burden but also secretory activity of the tumor [9-13]. In addition, plasma CgA may be an indicator for prognosis mainly in small intestinal NEN $[9,11$, 14]. Furthermore, an increase in the CgA level has been suggested as the first indicator of recurrence [15]. However, fluctuations in plasma CgA are frequently seen and in case of more than $25 \%$ increase from the previous level, determination of $\mathrm{CgA}$ should be repeated. If still increased, imaging with CT/MRI or SRI is recommended. Plasma CgA may also be elevated without the presence of NEN, for example due to the use of proton pump inhibitors, chronic atrophic gastritis, or decreased kidney and liver function $[16,17]$.

In some clinical trials with new targeted agents, significant reductions in $\mathrm{CgA}$ have been associated with better outcomes [14]. However, variations in plasma CgA without changes in imaging or symptoms compared to baseline levels should not be considered for treatment modification. Since several assay kits exist, but with no international standard, caution is recommended when comparing values from kits of different manufacturers [10]. Furthermore, each CgA kit has to be evaluated concerning sensitivity and specificity. CgA levels and normal ranges differ in the literature and from laboratory to laboratory and from assay to assay because they are measured by different

ENETS: Follow-up and Documentation methods. Therefore, "cutoff levels" recommended for decision-making should be applied with caution, and each institution has to define its own "cutoff levels."

\section{Chromogranin B}

Plasma chromogranin $\mathrm{B}(\mathrm{CgB})$ may be of value in the follow-up of BP and rectal NEN [18]. However, the availability for $\mathrm{CgB}$ is limited.

\section{Neuron-Specific Enolase}

Plasma neuron-specific enolase may act as an additional marker in patients with G3 NEN [19] and has been shown to be a prognostic marker in GEP NEN [14, 20].

\section{5-Hydroxyindoleacetic Acid}

Twenty-four-hour urine 5-hydroxyindoleacetic acid (5-HIAA) is an established marker for patients with serotonin-producing small intestinal/appendiceal and BP NEN, in particular in the presence of the "carcinoid syndrome." However, the sensitivity is less than that of plasma CgA [21]. Recently, analyses for serum 5-HIAA have been introduced [22]. Urine 5-HIAA is influenced by a number of dietary factors, for example avocado, banana, tomato and others, and by drugs such as coumarin, paracetamol, phenacetin, aspirin and others.

\section{Serotonin}

Measurement of serum serotonin is not recommended for follow-up [23].

\section{Gastrointestinal Hormones}

In patients with functioning pancreaticoduodenal tumors (insulinoma, gastrinoma, glucagonoma, VIPoma, somatostatinoma, etc.), the respective hormones are used as diagnostic markers. However, the prognostic value of change in hormone values is uncertain.

\section{NT-pro-Brain Natriuretic Peptide}

Measurement of NT-pro-brain natriuretic peptide (NT-pro-BNP) once yearly or at least every 2 nd year is recommended in the follow-up of patients with carcinoid syndrome to reveal development and to control carcinoid heart disease [24]. It is supplemented by echocardiography or eventually MRI of the heart [25-27].

\section{Imaging}

For G1 and G2 neuroendocrine tumors, which are generally slow growing, follow-up imaging is usually between 6 and 12 months but some patients may require imaging evaluation earlier. Better determination of the

Neuroendocrinology 2017;105:310-319 
timing of morphological evaluation is required in studies either retrospectively or prospectively.

\section{Cross-Sectional Imaging}

Current imaging procedures encompass CT, MRI, abdominal ultrasound (US), with or without contrast enhancement, and SRI. Primarily CT is used because of its standardized imaging planes that facilitate comparison between examinations and since the tissue resolution is better in cases of extended tumor load. Additionally, MRI may be preferable in younger patients having several imaging procedures, to reduce radiation dose. In addition, MRI is superior to CT to evaluate liver metastases, pancreatic and rectal NEN. Abdominal US may, however, be used for follow-up if documentation allows one to compare findings obtained during different follow-up visits. US is also valuable for the occasional patients in whom liver metastases are better visualized by US than by CT and for biopsy of new or rapidly growing lesions.

Thoracoabdominal CT, including three-phase examination of the liver, is the preferred imaging for follow-up as it is widely available and has relatively low cost. However, in many centers, abdominal MRI is preferred and if resection of liver metastases is considered during followup, it is generally recommended to perform MRI to reveal small liver metastases not visualized by CT [28].

\section{Functional Imaging}

Somatostatin receptor scintigraphy (SRS) with ${ }^{111}$ Inpentetreotide (octreotide scintigraphy), including planar imaging and SPECT, has been the mainstay for SRI although most NEN centers currently perform PET-CT with ${ }^{68} \mathrm{Ga}$-DOTA-conjugated peptide (e.g., TOC/NOC/ TATE) as this PET imaging technique is superior to SRS showing higher sensitivity, spatial resolution, identification of more lesions, less radiation, and a shorter investigation time [29-32] and is therefore preferred in followup. Other PET tracers, such as ${ }^{64} \mathrm{Cu}$-DOTATATEPET-CT $[30,31],{ }^{18}$ F-DOPA-PET-CT $[33-35]$ and ${ }^{11} \mathrm{C}-$ 5-HTP-PET [36] as well as GLP-1 receptor imaging with ${ }^{111}$ In-DTPA-exendin-4 SPECT-CT [37], may be used in follow-up if positive at baseline and if available at the center. Currently, there are only limited data available of PET-based imaging for routine follow-up, and its significance in this respect is currently not possible to define. However, PET may reveal metastases not seen on SRS or CT, particularly in bone and lymph nodes [30, 31, 33-35]. Grade uptake at SRI as well as homogeneity of uptake should be specified [38], also to evaluate the eligibility for peptide receptor radionuclide treatment.
Neuroendocrinology 2017;105:310-319 DOI: $10.1159 / 000458155$
${ }^{18}$ FDG-PET-CT has a higher sensitivity than SRS in patients with G3 NEN and should instead be utilized for follow-up in this group of patients [39]. Furthermore, ${ }^{18}$ FDG-PET-CT is frequently positive in G2 NEN with a high Ki-67 index and in aggressive and rapidly growing NEN $[39,40]$. In addition, ${ }^{18}$ FDG-PET is an important prognostic factor in NEN, as patients with a positive PET have a significantly poorer prognosis than patients with a negative one $[39,41]$. Additionally, evidence of different uptake in ${ }^{18}$ FDG-PET and SRI in the same patient reflects the tumor heterogeneity and could have an impact in decision-making criteria [42]. However, ${ }^{18}$ FDG-PET-CT is not commonly used for follow-up and in general only when SRI is negative, in patients with G3 NEN or in other selected subgroups of patients.

\section{Endoscopy}

Upper endoscopy should be utilized in the follow-up and control of gastric NEN and colonoscopy and sigmoidoscopy should be used for the follow-up of patients with colorectal NEN. National follow-up strategies should be followed to early diagnose metachronously appearing secondary gastrointestinal malignancy. Follow-up bronchoscopy for recurrence is indicated in patients with BP neuroendocrine tumors localized preoperatively by bronchoscopy.

Endoscopic ultrasonography, eventually with biopsy, of the stomach, duodenum, pancreas, and rectum could be useful for follow-up in selected patients ( $\mathrm{T}$ and $\mathrm{N}$ staging) and also in patients with MEN-1. Capsule endoscopy (jejunum/ileum) is rarely indicated in the follow-up. Endoscopic bronchial ultrasonography may be indicated in follow-up if biopsy of pathologic peribronchial lymph nodes is required.

\section{Histopathology}

In patients with tumor or metastatic recurrence and/ or rapid or unexpected progression imaging-guided biopsy should be considered to re-evaluate the Ki-67 proliferation index. An increase may change the treatment strategy or may rule out secondary malignances. Biopsies should be taken from new or rapidly growing metastases.

\section{Echocardiography}

"Carcinoid heart disease" with involvement of the tricuspid and pulmonary valves is observed in up to $10-20 \%$ of patients with the carcinoid syndrome [43]. In all patients with carcinoid syndrome and in patients with G1/ G2 GEP NEN or BP NEN with high 24-h urine, 5-HIAA level echocardiography should be performed at diagnosis
316
Knigge et al. 


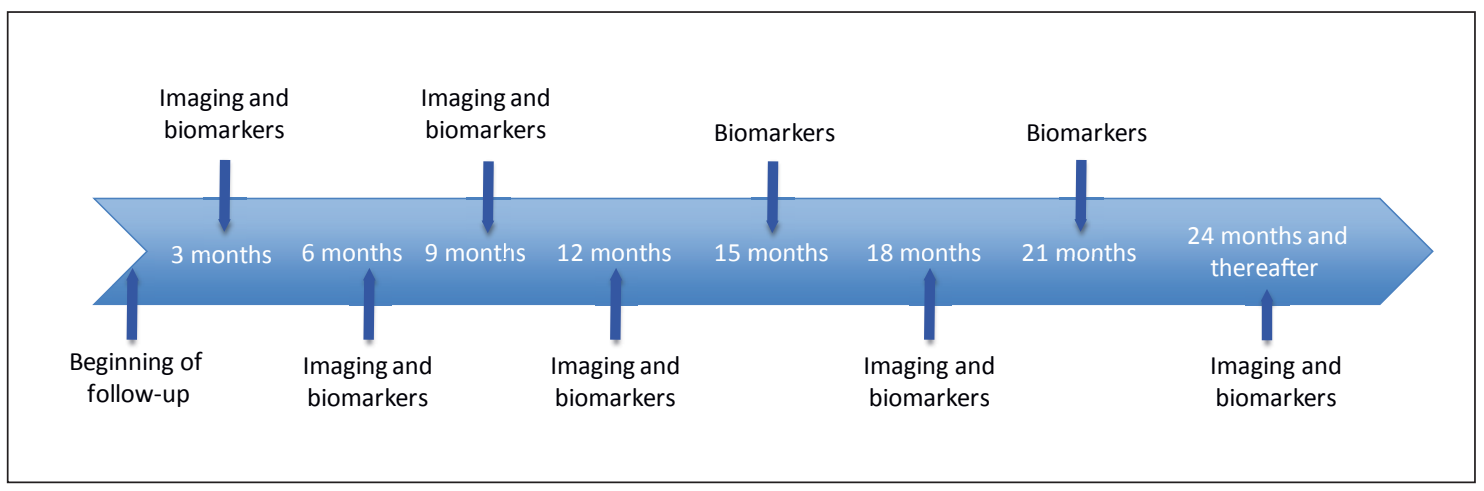

Fig. 1. Proposed timeline schedule for the follow-up of patients with G1/G2 gastroenteropancreatic neuroendocrine neoplasms and bronchopulmonary (typical and atypical) carcinoids regarding tumor progression rate. Initial follow-up every 3 months with clinical assessment, imaging and biomarkers is suggested to define progression rate. If stable disease has been confirmed after 15 months, imaging control could be performed every 6-12 months and clinical and biomarker evaluation every 3-6 months.

and thereafter annually or shorter if clinically indicated [25-27]. The measurement of NT-pro-BNP should be performed as well [24].

\section{Progression Rate}

Progression disease rates within G1/G2 GEP NEN and BP NEN are not always well defined only using the grading system. Stable and slowly growing tumors should be differentiated from more aggressive tumors in follow-up schedules, i.e., patients with aggressive and rapidly growing tumors should have a follow-up with imaging every 3 months while patients with stable or slowly growing tumors may have imaging every 6-12 months (Tables 1,2 ). Efforts to quantify the rate of progression should be performed. Furthermore, if stable disease is seen over longer time, the interval between follow-up visits and imaging may be further extended. Trying to define the progression rate and the influence in follow-up for metastatic disease, a proposed timeline for follow-up regarding tumor progression is given in Figure 1.

\section{Hereditary Diseases}

Patients with hereditary diseases such as multiple endocrine neoplasia type 1 (MEN-1), von Hippel-Lindaus syndrome (VHL), or neurofibromatosis type 1 should be followed according to the organ of the primary tumor, for example the pancreas and duodenum. Guidelines for the follow-up of non-GEP disease or manifestations, for example parathyroid or pituitary adenomas in MEN-1, brain and kidney manifestations in VHL and GIST in neurofibromatosis type 1 , are not described in these recommendations as they are beyond the scope of this review and are dealt with in several other guidelines.

\section{Tumor-Specific Recommendations}

The recommended follow-up for NEN, including GEP NEN, BP (typical and atypical) carcinoids, large-cell neuroendocrine carcinomas as well as thymic NEN, is given in Table 1. The panel agrees that the level of evidence for follow-up recommendations is low. The recommendations are in accordance with those given in the WHO 2010 classification of GEP NEN, the ENETS 2016 guidelines for GEP NEN [3] and the recent guidelines for BP NEN [7].

Follow-up is life-long for most patients, with the exceptions mentioned in Table 1. The comprehensive Table 1 on follow-up is based on the organ of the primary tumor and is intended to give a simple overview or cata$\log$ for the clinician. Therefore, some of the schemes are repeated from one organ to the other. The panel did not distinguish in the follow-up between patients with G1 and G2 GEP NEN, whereas patients with G3 GEP NEN were considered as a separate group.

In general, follow-up for resected or nonresected tumors are placed in the same group, but the intervals between follow-ups are in general shorter in patients with 
residual tumor or metastases compared to patients with curatively resected tumor or metastases as well as in patients with aggressive disease (Table 2).

The follow-up investigations that should be documented to visualize the specific course of the disease in an individual patient are summarized in Tables 1 and 2 and in Figure 1.

\section{Disclosure Statement}

The authors have no conflicts of interest.

\section{Appendix}

\section{Antibes Consensus Conference Participants}

Arnold, R. (Munich, Germany); Borbath, I. (Service de Gastroenterologie, Cliniques Universitaires St-Luc, Bruxelles, Belgium); Caplin, M. (Neuroendocrine Tumour Unit, Royal Free Hospital, London, UK); Chen, Y.-J. (Peking Union Medical College Hospital, Chinese Academy of Medical Sciences, Beijing, China); Costa, F. (Hospital Sírio Libanês, São Paulo, Brazil); Couvelard, A. (Service de Pathologie, Hôpital Bichat, Paris, France); Cwikla, J.B. (Department of Radiology, Faculty of Medical Sciences, University of Warmia and Mazury, Olsztyn, Poland); Davies, P. (Neuroendocrine Tumour Unit, Royal Free Hospital, London, UK); de Herder, W.W. (Department of Internal Medicine, Division of Endocrinology, ENETS Centre of Excellence Rotterdam, Erasmus MC, Rotterdam, The Netherlands); Delle Fave, G. (Department of Digestive and Liver Disease, Ospedale Sant'Andrea, Rome, Italy); Eriksson, B. (Department of Endocrine Oncology, Uppsala University Hospital, Uppsala, Sweden); Fazio, N. (Unit of Gastrointestinal Medical Oncology and Neuroendocrine Tumors, European Institute of Oncology, Milan, Italy); Ferone, D. (Department of Endocrine and Metabolic Sciences, University of Genoa, Genoa, Italy); Garcia-Carbonero, R. (Medical Oncology Department, Hospital Universitario Doce de Octubre, Madrid, Spain); Grozinsky-Glasberg, S. (Neuroendocrine Tumor Unit, Endocrinology and Metabolism Service, Department of Medicine, Hadassah-Hebrew University Medical Center, Jerusalem, Israel); Gorbunova, V. (Department of Oncology, Institution of Russian Academy of Medical Sciences, Moscow, Russia); Gross, D. (Department of Endocrinol- ogy and Metabolism, Hadassah University Hospital, Mevasseret Zion, Israel); Grossman, A. (Oxford Centre for Diabetes, Endocrinology and Metabolism, Churchill Hospital, Oxford, UK); Hicks, R.J. (Cancer Imaging, the Peter MacCallum Cancer Centre, Melbourne, VIC, Australia); Hörsch, D. (Gastroenterology and Endocrinology Center for Neuroendocrine Tumors Bad Berka, Bad Berka, Germany); Tiensuu Janson, E. (Department of Endocrine Oncology, Uppsala University Hospital, Uppsala, Sweden); Jensen, R.T. (Digestive Diseases Branch, NIH, Bethesda, MD, USA); Kaltsas, G. (Department of Pathophysiology, Division of Endocrinology, National and Kapodistrian University of Athens, Athens, Greece); Krenning, E.P. (Cyclotron Rotterdam BV, Erasmus MC, Rotterdam, The Netherlands); Kulke, M.H. (Dana-Farber Cancer Institute, Harvard Medical School, Boston, MA, USA); Kwekkeboom, D.J. (Department of Internal Medicine, Division of Nuclear Medicine, ENETS Centre of Excellence Rotterdam, Erasmus MC, Rotterdam, The Netherlands); Lombard-Bohas, C. (Medical Oncology Department, Hôpital Edouard Herriot, Hospices Civils de Lyon, Lyon, France); Öberg, K. (Department of Medical Sciences, Endocrine Oncology Unit, University Hospital, Uppsala, Sweden); O'Connor, J. (Department of Clinical Oncology, Institute Alexander Fleming, Buenos Aires, Argentina); Pape, U.-F. (Department of Hepatology and Gastroenterology, Campus Virchow Klinikum, Charité Universitätsmedizin Berlin, Berlin, Germany); Pavel, M. (Department of Hepatology and Gastroenterology, Campus Virchow Klinikum, Charité Universitätsmedizin Berlin, Berlin, Germany); Perren, A. (Institute of Pathology, University of Bern, Bern, Switzerland); Ramage, J. (Gastroenterology Department, Hampshire Hospitals NHS Trust, Hampshire, UK); Rindi, G. (Institute of Anatomic Pathology, Policlinico A. Gemelli, Università Cattolica del Sacro Cuore, Rome, Italy); Rinke, A. (Division of Gastroenterology and Endocrinology, University Hospital Marburg [UKGM], Marburg, Germany); Ruszniewski, P. (Department of Gastroenterology, Beaujon Hospital, Clichy, France); Scoazec, J.-Y. (Services de Pathologie Morphologique et Moléculaire, Département de Biologie et Pathologie Médicales, Gustave Roussy Cancer Campus, Villejuif, France); Sorbye, H. (Department of Oncology, Haukeland University Hospital, Bergen, Norway); Toumpanakis, C. (Neuroendocrine Tumour Unit, Royal Free Hospital, London, UK); Valle, J.W. (Department of Medical Oncology, The Christie NHS Foundation Trust, University of Manchester/Institute of Cancer Sciences, Manchester, UK); Welin, S. (Department of Medical Sciences, Endocrine Oncology, Uppsala University, Uppsala, Sweden); Wiedenmann, B. (Department of Hepatology and Gastroenterology, Campus Virchow Klinikum, Charité Universitätsmedizin Berlin, Berlin, Germany).

\section{References}

1 Bosman FT, Carneiro F, Hruban R, Theise N: WHO Classification of Tumours of the Digestive System, ed 4. Lyon, International Agency for Research on Cancer (IARC), 2010.

2 Salazar R, Wiedenmann B, Rindi G, Ruszniewski P: ENETS 2011 Consensus Guidelines for the Management of Patients with Digestive Neuroendocrine Tumors: an update. Neuroendocrinology 2012;95:71-73.
3 O’Toole D, Kianmanesh R, Caplin M: ENETS 2016 Consensus Guidelines for the Management of Patients with Digestive Neuroendocrine Tumors: an update. Neuroendocrinology 2016;103:117-118.

4 Rindi G, Kloppel G, Alhman H, et al: TNM staging of foregut (neuro)endocrine tumors: a consensus proposal including a grading system. Virchows Arch 2006;449:395-401.
5 Rindi G, Klöppel G, Couvelard A, Komminoth $\mathrm{P}$, et al: TNM staging of midgut and hindgut (neuro) endocrine tumors: a consensus proposal including a grading system. Virchows Arch 2007;451:757-762.

6 Arnold R, Chen YJ, Costa F, et al: ENETS Consensus Guidelines for the Standards of Care in Neuroendocrine Tumors: follow-up and documentation. Neuroendocrinology 2009;90:227-233 
7 Caplin ME, Baudin E, Ferolla P, et al: Pulmonary neuroendocrine (carcinoid) tumors: European Neuroendocrine Tumor Society expert consensus and recommendations for best practice for typical and atypical pulmonary carcinoids. Ann Oncol 2015;26:16041620.

8 Tabaksblat EM, Langer SW, Knigge U, et al: Diagnosis and treatment of bronchopulmonary neuroendocrine tumours: state of the art. Acta Oncol 2016;55:3-14.

9 Arnold R, Wilke A, Rinke A, et al: Plasma chromogranin A as marker for survival in patients with metastatic endocrine gastroenteropancreatic tumors. Clin Gastroenterol Hepatol 2008;6:820-827.

10 Oberg K, Janson ET, Eriksson B: Tumour markers in neuroendocrine tumours. Ital Gastroenterol Hepatol 1999; 31(suppl 2):S160-S162.

11 Janson ET, Holmberg L, Stridsberg M, et al: Carcinoid tumors: analysis of prognostic factors and survival in 301 patients from a referral center. Ann Oncol 1997;8:685-690.

12 Jensen KH, Hilsted L, Jensen C, et al: Chromogranin A is a sensitive marker of progression or regression in ileo-cecal neuroendocrine tumors. Scand J Gastroenterol 2013;48: 70-77.

13 Yao JC, Lombard-Bohas C, Baudin E, et al: Daily oral everolimus activity in patients with metastatic pancreatic neuroendocrine tumors after failure of cytotoxic chemotherapy: a phase II trial. J Clin Oncol 2010;28:69-76.

14 Yao JC, Pavel M, Phan AT, et al: Chromogranin A and neuron-specific enolase as prognostic markers in patients with advanced pNET treated with everolimus. J Clin Endocrinol Metab 2011;96:3741-3749.

15 Welin S, Stridsberg M, Cunningham J, et al: Elevated plasma chromogranin A is the first indication of recurrence in radically operated midgut carcinoid tumors. Neuroendocrinology 2009;89:302-307.

16 Campana D, Nori F, Piscitelli L, et al: Chromogranin A: is it a useful marker of neuroendocrine tumors? J Clin Oncol 2007;25:19671973.

17 Marotta V, Nuzzo V, Ferrara T, et al: Limitations of chromogranin A in clinical practice. Biomarkers 2012;17:186-191.

18 Bech PR, Martin NM, Ramachandran R, Bloom SR: The biochemical utility of chromogranin $\mathrm{A}$, chromogranin $\mathrm{B}$ and cocaineand amphetamine-regulated transcript for neuroendocrine neoplasia. Ann Clin Biochem 2014;51:8-21.

19 Baudin E, Gigliotti A, Ducreux M, et al: Neuron-specific enolase and chromogranin $\mathrm{A}$ as markers of neuroendocrine tumours. Br Cancer 1998;78:1102-1107.
20 Yao JC, Shah MH, Ito T, et al: Everolimus for advanced pancreatic neuroendocrine tumors. N Engl J Med 2011;364:514-523.

21 Bajetta E, Ferrari L, Martinetti A, et al: Chromogranin A, neuron specific enolase, carcinoembryonic antigen, and hydroxyindole acetic acid evaluation in patients with neuroendocrine tumors. Cancer 1999;86:858-865.

22 Tohmola N, Johansson A, Sane T, et al: Transient elevation of serum 5-HIAA by dietary serotonin and distribution of 5-HIAA in serum protein fractions. Ann Clin Biochem 2015;52:428-433.

23 Bhattacharyya S, Jagroop A, Gujral DM, et al: Circulating plasma and platelet 5-hydroxytryptamine in carcinoid heart disease: a pilot study. J Heart Valve Dis 2013;22:400-407.

24 Dobson R, Burgess MI, Banks M, et al: The association of a panel of biomarkers with the presence and severity of carcinoid heart disease: a cross-sectional study. PLoS One 2013; 8:e73679.

25 Dero I, De Pauw M, Borbath I, et al: Carcinoid heart disease - a hidden complication of neuroendocrine tumours. Acta Gastroenterol Belg 2009;72:34-38.

26 Plockinger U, Gustafsson B, Ivan D, et al: ENETS Consensus Guidelines for the Standards of Care in Neuroendocrine Tumors: echocardiography. Neuroendocrinology 2009;90: 190-193.

27 Bhattacharyya S, Toumpanakis C, Chilkunda $\mathrm{D}$, et al: Risk factors for the development and progression of carcinoid heart disease. Am J Cardiol 2011;107:1221-1226.

28 Dromain C, de Baere T, Lumbroso J, et al: Detection of liver metastases from endocrine tumors: a prospective comparison of somatostatin receptor scintigraphy, computed tomography, and magnetic resonance imaging. J Clin Oncol 2005;23:70-78.

29 Geijer H, Breimer LH: Somatostatin receptor $\mathrm{PET} / \mathrm{CT}$ in neuroendocrine tumours: update on systematic review and meta-analysis. Eur J Nucl Med Mol Imaging 2013;40:1770-1780.

30 Pfeifer A, Knigge U, Mortensen J, et al: Clinical PET of neuroendocrine tumors using ${ }^{64} \mathrm{Cu}$-DOTATATE: first-in-humans study. J Nucl Med 2012;53:1207-1215.

31 Pfeifer A, Knigge U, Binderup T, et al: ${ }^{64} \mathrm{Cu}$ DOTATATE PET for neuroendocrine tumors: a prospective head-to-head comparison with ${ }^{111}$ In-DTPA-octreotide in 112 patients. J Nucl Med 2015;56:847-854.

32 Johnbeck CB, Knigge U, Kjaer A: PET tracers for somatostatin receptor imaging of neuroendocrine tumors: current status and review of the literature. Future Oncol 2014;10:22592277.
33 Santhanam P, Chandramahanti S, Kroiss A, et al: Nuclear imaging of neuroendocrine tumors with unknown primary: why, when and how? Eur J Nucl Med Mol Imaging 2015;42: 1144-1155.

34 Haug A, Auernhammer CJ, Wangler B, et al: Intraindividual comparison of ${ }^{68} \mathrm{Ga}$-DOTATATE and ${ }^{18} \mathrm{~F}$-DOPA PET in patients with well-differentiated metastatic neuroendocrine tumours. Eur J Nucl Med Mol Imaging 2009;36:765-770.

35 Ambrosini V, Tomassetti P, Castellucci P, et al: Comparison between ${ }^{68} \mathrm{Ga}$-DOTA-NOC and ${ }^{18} \mathrm{~F}$-DOPA PET for the detection of gastro-entero-pancreatic and lung neuro-endocrine tumours. Eur J Nucl Med Mol Imaging 2008;35:1431-1438.

36 Orlefors H, Sundin A, Garske U, et al: Wholebody (11)C-5-hydroxytryptophan positron emission tomography as a universal imaging technique for neuroendocrine tumors: comparison with somatostatin receptor scintigraphy and computed tomography. J Clin Endocrinol Metab 2005;90:3392-3400.

37 Wild D, Christ E, Caplin ME, et al: Glucagonlike peptide-1 versus somatostatin receptor targeting reveals 2 distinct forms of malignant insulinomas. J Nucl Med 2011;52:1073-1078.

38 Chougnet CN, Leboulleux S, Caramella C, et al: Frequency and characterization of gastroentero-pancreatic neuroendocrine tumor patients with high-grade of uptake at somatostatin receptor scintigraphy. Endocr Relat Cancer 2013;20:229-239.

39 Binderup T, Knigge U, Loft A, et al: ${ }^{18} \mathrm{~F}$-fluorodeoxyglucose positron emission tomography predicts survival of patients with neuroendocrine tumors. Clin Cancer Res 2010;16: 978-985.

40 Abgral R, Leboulleux S, Deandreis D, et al: Performance of (18)fluorodeoxyglucose-positron emission tomography and somatostatin receptor scintigraphy for high Ki67 ( $\geq 10 \%)$ well-differentiated endocrine carcinoma staging. J Clin Endocrinol Metab 2011;96: 665-671.

41 Binderup T, Knigge U, Loft A, et al: Functional imaging of neuroendocrine tumors: a headto-head comparison of somatostatin receptor scintigraphy, ${ }^{123}$ I-MIBG scintigraphy, and ${ }^{18}$ F-FDG PET. J Nucl Med 2010;51:704-712.

42 Kubota K, Okasaki M, Minamimoto R, et al: Lesion-based analysis of (18)F-FDG uptake and (111)In-pentetreotide uptake by neuroendocrine tumors. Ann Nucl Med 2014;28: 1004-1010.

43 Grozinsky-Glasberg S, Grossman AB, Gross DJ: Carcinoid heart disease: from pathophysiology to treatment - 'something in the way it moves.' Neuroendocrinology 2015;101:263273.

ENETS: Follow-up and Documentation 